\title{
La prueba en el proceso penal
}

1. La prueba, como es sabido, es la actividad procesal que tiene por objeto conseguir la convicción del juzgador sobre la realidad de los hechos en que se fundamentan las pretensiones de las partes a las que aquél debe dar una respuesta fundada en Derecho. En principio, esta definición conviene a los distintos tipos de proceso (civil, penal, laboral, etc.) y responde al principio "da mihi factum, tibi dabo ius", que en buena medida compendía la función jurisdiccional.

Ello no obstante, es preciso señalar inmediatamente que en cada uno de los distintos procesos existen especiales singularidades que vienen a configurar, en definitiva, tipos de procesos distintos. Así, en el proceso civil cabe destacar los principios "dispositivo" y de la "verdad formal", que en modo alguno puede predicarse - como luego veremos- del proceso penal, en el que prevalece el principio de la "verdad material" y donde las facultades del órgano jurisdiccional, en materia probatoria, son muy superiores a los del Juez civil, por ejemplo.

2. Los medios probatorios, en líneas generales, son similares en los dis- 
tintos procesos: confesión, testigos, peritos, documentos, reconocimiento judicial, etc. Sin embargo, es preciso destacar inmediatamente la amplitud de medios probatorios admisible en el derecho penal, así como las peculiaridades que sobre los comunes han de reconocerse en el proceso penal. Así, en la confesión, es bien distinto su alcance en el campo civil (art. 1232 C. Civil), donde la confesión hace prueba contra su autor, y en el penal (art. 406 L.E.Crim.), al decirse en éste que la confesión del procesado no dispensará al Juez de Instrucción de practicar todas las diligencias necesarias a fin de adquirir el convencimiento de la verdad de la confesión y de la existencia del delito. De modo similar, respecto de los testigos, en el campo civil se declara la inhabilidad de determinadas personas para ser testigos (v. arts. 1246 y 1247 C. Civil), limitaciones que, en principio, no se establecen en el campo penal, con independencia, lógicamente, del valor probatorio que el juzgador pueda reconocer a las distintas personas. Por lo demás, debe destacarse también que en el proceso penal tiene plena validez la prueba indiciaria o circunstancial (STC 174/85, 17 de diciembre -motivación-: 229/88, 1 diciembre; 107/89, 8 junio; 94/90, 23 mayo; entre otras).

3. Por su parte, el procedimiento probatorio, es decir, el conjunto de trámites procesales en que se articula la actividad probatoria, responde también, en principio, a un esquema común a los distintos procesos: proposición, admisión y práctica. No obstante, en el proceso penal existe una peculiaridad que oscurece sensiblemente este simplista esquema, pues, al estar dividido el mismo en dos fases (instrucción, o preparatoria, y del juicio oral, o plenaria), en las que se practican diligencias formalmente idénticas (declaración, testimonios, pericias, etc.), alguna de las cuales no son susceptibles de repetición en la fase de plenario (v. gr. la inspección ocular y levantamiento de un cadáver, la autopsia del mismo, etc.), se plantean a veces serias dificultades en orden a la interpretación y valoración de tales diligencias que no siempre encuentran en la doctrina y en la jurisprudencia unos criterios armónicos.

A este respecto, tiene particular relevancia el art. 188 L.E.Crim., cuyo texto actualmente vigente fue introducido por la Ley 53/1978, de 4 de diciembre, en cuanto implica la posibilidad de personación e intervención 
del inculpado en las actividades de la fase de instrucción del proceso penal, lo que potencia extraordinariamente las posibilidades de defensa, tanto en orden a la iniciativa sobre práctica de determinadas diligencias como en el ejercicio del derecho de contradicción en las declaraciones de testigos y coimputados ante la autoridad judicial (v. art. 6.3.d del Convenio para la Protección de los Derechos Humanos y de las Libertades Fundamentales).

4. Constituye un aspecto de singular relevancia, especialmente en el proceso penal, el obligado respecto de los derechos y garantías reconocidos constitucionalmente, que abarca no solamente el texto de nuestra Norma Fundamental, sino que alcanza igualmente a los tratados y acuerdos internacionales sobre el particular (v. art. 10, $\mathrm{pf}^{\mathrm{o}}$ se. C.E.). El art. 120 C.E. destaca convenientemente las exigencias de publicidad, oralidad y de motivación de las resoluciones judiciales. Y el artículo 24 de la Constitución - uno de los de más frecuente cita ante los Tribunales- reconoce, entre otros, el derecho a obtener la tutela judicial efectiva de los jueces y tribunales, con expresa proscripción de la indefensión. El derecho al juez ordinario predeterminado en la Ley, a ser informada convenientemente la persona de la acusación formulada contra ella, a un proceso público sin dilaciones indebidas y con todas las garantías, el derecho a la prueba. etc. En este sentido, destaca acertadamente Ramón Méndez la importancia del "juicio oral" en la estructura del proceso penal, como ha puesto de manifiesto con singular precisión la $s^{\mathrm{n}}$ T.C. 16/1981, de 18 de mayo. En este contexto, sin embargo, dice el autor citado que “... ello no obsta para que se practiquen pruebas anticipadamente a las sesiones del juicio oral, o de que determinados medios probatorios de difícil o imposible repetición deban estar rodeados de todas las garantías de contradicción en el momento de su realización para que valgan como pruebas. El momento en que se practica la prueba no condiciona su carácter. Lo que en todo caso hay que resaltar es que el juicio oral necesita de una actividad probatoria mínima en lo que se refiere a la acusación. Es intrascendente apelar a las diligencias sumariales. La acusación necesita siempre pruebas y sólidas. El albur de que no existan o de que no se logren aportar se resuelve siempre en la presunción de inocencia. Desde otro punto de vista, el único límite a la 
actividad probatoria es la licitud de los medios empleados a tal fin. Vale la pena recordar que el art. 11.1 L.O.P.J. dispone que no surtirán efecto las pruebas obtenidas, directa o indirectamente, violentando los derechos o libertades fundamentales. La actividad probatoria está rodeada de nobleza, constitucionalmente hablando (El Proceso Penal. Lectura constitucional. Fo Ramos Méndez. Edt. J. M" Bosch. Barcelona. 1991).

El Tribunal Constitucional, al examinar, especialmente a través de los recursos de amparo, el alcance del derecho a la presunción de inocencia, a la proscripción de toda indefensión y a la necesidad de motivar las sentencias, ha ido marcando las líneas maestras que - de acuerdo con las exigencias constitucionales- deben configurar el proceso penal en nuestro ordenamiento jurídico.

Conforme a la doctrina del Tribunal Constitucional, pueden señalarse como líneas maestras del proceso penal, las siguientes: a) principio de libre valoración de la prueba (arts. 117.3 C.E. y 741 L.E.Crim.): b) únicamente pueden considerarse auténticas pruebas que vinculen a los órganos de la justicia penal las practicadas en el juicio oral (art. 741 L.E.Crim.): c) las diligencias sumariales son actos de investigación encaminados a la averiguación del delito e identificación del delincuente (art. 299 L.E.Crim.); d) sólo cuando las diligencia o actuaciones sumariales son de imposible o muy difícil reproducción en el juicio oral, es posible traerlas al mismo como prueba anticipada o preconstituida (art. 730 L.E.Crim.); e) la carga material de la prueba corresponde exclusivamente a la acusación; f) para que las diligencias sumariales puedan tener eficacia probatoria, es preciso que sean reproducidas en el acto de la vista en condiciones que permitan a la defensa del acusado someterlas a contradicción.

Salvo las excepciones legalmente previstas, el proceso debe ser público (la publicidad implica que los juicios sean conocidos más allá del círculo de los presentes en los mismos, pudiendo tener una proyección general —s. T.C. 30/82, 1 junio-), y predominantemente oral (en este aspecto, se ha dicho que las actividades instructoras no son públicas y quedan al margen del procedimiento "predominantemente oral" (s. T.C. 154/88, 12 de julio). La exigencia de motivación de las sentencias, por su parte, cumple 
una doble finalidad: de un lado, exteriorizar el fundamento de la decisión adoptada, haciendo explícito que responde a una determinada interpretación jurídica y permitiendo su eventual control. De otro lado, posibilitar al ciudadano conocer las razones de la resolución por la que resulta condenado o absuelto. En las sentencias penales, el requisito de la motivación impone al juzgador la realización de un doble juicio. De una parte, la existencia de una motivación fáctica o antecedentes de hecho, inferida a partir de la prueba practicada (arts. 248.3 L.O.P.J. y 142.2 L.E.Crim.), haciendo declaración expresa y terminante de los que se estimen probados. De otra parte, una valoración jurídica suficientemente razonada acerca de los hechos declarados probados (s. T.C. 174/92. 2 de noviembre).

A este respecto, es importante destacar la diversa trascendencia que esta exigencia comporta según se trate de prueba directa o indirecta. En el primer caso (v. gr. casos de declaraciones de testigos presenciales del hecho a enjuiciar), en muchas ocasiones poco será lo que el juzgador pueda decir para explicar las razones de su convicción. No sucede así, en cambio, tratándose de prueba indirecta (es decir, cuando el juzgador forma su convicción partiendo de unos hechos indiciarios debidamente acreditados en la causa), por cuanto dichos indicios - aparte de estar acreditados por prueba directa- han de llevar a la convicción sobre el hecho consecuencia - que el juzgador estime acreditado- a través de un razonamiento acorde con las reglas de la lógica y las enseñanzas de la experiencia, según las reglas del criterio humano (art. $1253 \mathrm{C}$. Civil); razonamiento que el juzgador deberá explicitar, con objeto de posibilitar su revisión ante el órgano superior e, incluso, en la vía casacional.

Al estudiar la prueba en el proceso penal, es preciso hacer referencia, siquiera sea ésta sucinta, a las exigencias legales y constitucionales de los diferentes medios probatorios, que constituyen otras tantas garantías para el justiciable. el cual no puede ser condenado sin una prueba suficiente, obtenida con las debidas garantías. 
En este sentido, aparte de lo anteriormente dicho sobre la valoración de la prueba, carga de la misma, momento de practicarse, principios de publicidad, inmediación, oralidad y contradicción, así como sobre motivación de las sentencias (art. 120 C.E.), procede destacar lo siguiente:

1. a) que todos los ciudadanos y los poderes públicos están sujetos a la Constitución, así como al resto del ordenamiento jurídico (art. 9.1 C.E.). Que la Constitución garantiza el principio de legalidad, la jerarquía normativa, la publicidad de las normas, la irretroactividad de las disposiciones sancionadoras no favorables o restrictivas de derechos individuales, la seguridad jurídica, la responsabilidad y la interdicción de la arbitrariedad de los poderes públicos (art. 9.3. C.E.). Que las normas relativas a los derechos fundamentales y a las libertades que la Constitución reconoce se interpretarán de conformidad con la Declaración Universal de los Derechos Humanos y con los Tratados y Acuerdos Internacionales sobre las mismas materias ratificados por España (art. 10.2 C.E.). Que la Constitución es la norma suprema del ordenamiento jurídico y vincula a todos los Jueces y Tribunales, quienes interpretarán y aplicarán las leyes y los reglamentos según los preceptos y principios constitucionales, conforme a la interpretación de los mismos que resulte de las resoluciones dictadas por el Tribunal Constitucional, en todo tipo de procesos (art. 5.1 L.O.P.J.). Que existe la posibilidad de promover "cuestiones de inconstitucionalidad" (art. 5.2 L.O.P.J.). Que los derechos y las libertades reconocidos en el Capítulo II del Título I de la Constitución vinculan, en su integridad, a todos los Jueces y Tribunales y están garantizados bajo la tutela efectiva de los mismos (art. 7.1 L.O.P.J.). Que no surtirán efecto las pruebas obtenidas, directa o indirectamente, violando los derechos o libertades fundamentales (art. 11.1 L.O.P.J.).

El fundamental art. 24 de la Constitución reconoce el derecho de todas las personas a la tutela judicial efectiva, con expresa proscripción de la indefensión; así como el derecho al Juez ordinario predeterminado en la Ley, el derecho de defensa letrada, el derecho a ser informados de la acusación, el derecho a un proceso público, sin dilaciones indebidas y 
con todas las garantías; el derecho a utilizar los medios de prueba pertinentes para su defensa, a no declarar contra sí mismos, a no confesarse culpables y, en definitiva, a la presunción de inocencia.

En todo caso, tiene singular relevancia los preceptos procesales relativos a las garantías y derechos del detenido (arts. 520 y ss. L.E.Crim.). así como las pertinentes garantías que deben concurrir en todos los casos de entradas y registros en los domicilios de los particulares, así como en los supuestos de detención y apertura de la correspondencia y de la interceptacion de las comunicaciones telefónicas (arts. 545 y ss. L.E.Crim.).

2. b) La Declaración Universal de los Derechos Humanos, por su parte, contempla una serie de garantías fundamentales para el ciudadano: la prohibición de detención o prisión arbitrarias (art. 9); la plena igualdad ante la ley, el derecho del acusado a audiencia pública, así como a ser juzgado por un Tribunal independiente e imparcial ("imparcialidad objetiva") (art. 10); el derecho del inculpado a la presunción de inocencia, a un juicio con todas las garantías de defensa, así como el principio de irretroactividad y el principio de legalidad de las penas (art. 11). Se reconoce también a toda persona el derecho a no sufrir injerencias arbitrarias en su vida privada, así como en la de su familia, en su domicilio, en su correspondencia, amén de su honra o reputación (art. 12).

3. c) El Convenio para la Protección de los Derechos Humanos y Libertades Fundamentales, suscrito en Roma en 1950, reconoce, entre otros, el derecho a la libertad individual (art. 5), así como a que las causas sean oídas equitativa y públicamente, en un plazo razonable, por Tribunal independiente e imparcial (art. 6). En todo caso, se reconoce a todo acusado el derecho a conocer la acusación que pese sobre él, al tiempo y a las facilidades necesarias para preparar su defensa, a defenderse por sí, por Letrado o por Abogado de oficio, a interrogar o hacer interrogar a los testigos que declaren contra él, a obtener la citación y el interrogatorio de los testigos que declaren en su favor en las mismas condiciones que los testigos que lo hagan en su contra; así como a disponer de un intérprete cuando no conozca la lengua del Tribunal que ha de juzgarle (art. 6.3). 
Como garantía del reconocimiento de todos estos derechos, el citado Convenio ha creado la Comisión y el Tribunal Europeo de Derechos Humanos.

4. d) El Pacto Internacional de Derechos Civiles y Políticos, suscrito en Nueva York en 1966, finalmente, viene a reconocer un estato jurídico similar al diseñado por la Declaración Universal de Derechos Humanos y el Convenio Europeo sobre esta materia (v. art. 14 PIDC y P).

MEDIOS DE PRUEBA

Respecto de los medios de prueba, dice el Código Civil que "las pruebas pueden hacerse por instrumentos, por confesión, por inspección personal del Juez, por peritos, por testigos y por presunciones" (art. 121j). La Ley de Enjuiciamiento Civil, por su parte, dispone que "los medios de prueba de que se podrán hacer uso en juicio son: $1^{\circ}$. Confesión. $2^{\circ}$. Documentos públicos y solemnes. $3^{\prime \prime}$. Documentos privados y correspondencia. $4^{\circ}$. Los libros de los comerciantes que se lleven con las formalidades prevenidas en la Sección Segunda, título II, libro $1^{\circ}$ del Código de Comercio. $5^{\circ}$. Dictamen de peritos. $6^{\circ}$. Reconocimiento Judicial. Y $7^{\circ}$. Testigos.

Ni el Código Penal ni la Ley de Enjuiciamiento Criminal contienen una enumeración similar para el campo penal, que, en principio, está abierto a un más amplio abanico de posibilidades probatorias. Ello, no obstante. como destaca Tomé García: "la Ley de Enjuiciamiento Criminal contiene... una regulación de los medios de prueba que podemos calificar de insuficiente por varios motivos: a) la regulación de cada medio de prueba es limitada ya que continuamente se refiere a la regulación del correspondiente acto de investigación sumarial... b) no regula, aunque sí menciona, la declaración del acusado como medio de prueba a practicar en el juicio oral, c) no contempla los problemas que plantea la práctica de los modernos medios de prueba: fotografía, vídeo, cintas magnetofónicas, télex...".

Los medios de prueba previstos en nuestra Ley de Enjuiciamiento Criminal, en todo caso, son los siguientes: a) Declaración del acusado; b) Prueba testifical; c) Careo; d) Prueba pericial; e) Prueba documen- 
tal; f) Inspección ocular. Por lo dernás, debe citarse también como prueba válida en el campo penal la denominada "Prueba por indicios" (v. s" T.C. 107/1989, de 8 de junio).

Seguidamente vamos a hacer una sucinta referencia a los distintos medios de prueba especialmente regulados en la Ley de Enjuiciamiento Criminal:

1. a) Declaración del acusado (arts. 688 a 700 L.E.Crim.). Los artículos 385,387 y 395 de esta Ley pueden plantear dudas sobre su constitucionalidad, habida cuenta de los derechos reconocidos al inculpado en el art. 24 C.E. (derecho a no declararse culpable, a no declarar contra sí mismo, etc.). Como dice Ramos Méndez, "sólo resta, pues, que el acusado quiera declarar voluntariamente para que sea viable este medio de prueba. Pero aún así, la disposición a declarar no le obliga a nada más que a decir lo que quiera, aunque no sea la verdad" (El Proceso Penal. Lectura constitucional. Ed. José $\mathrm{M}^{\mathrm{a}}$ Bosch. F. Ramos Méndez. Pág. 344).

Importa destacar que, según establece el art. 406 L.E.Crim., la confesión del procesado no dispensará al Juez de Instrucción de practicar todas las diligencias necesarias a fin de adquirir el convencimiento de la verdad de la confesión y de la existencia del delito.

Conforme a los artículos 655, 688 y 793.3 L.E.Crim., cabe la conformidad del acusado con la calificación acusadora. El último artículo, con mejor técnica que los anteriores, dice, en el marco del procedimiento abreviado, que "antes de iniciarse la práctica de la prueba, la acusación y la defensa con la conformidad del acusado presente, podrán pedir al Juez o Tribunal que proceda a dictar sentencia de conformidad con el escrito de acusación que contenga pena de mayor gravedad, o con el que se presentara en ese acto...".

2. b) Prueba testifical. Se entiende por testigo a la persona física que, sin ser parte en el proceso, es llamada a declarar, según su experiencia personal, acerca de la existencia y naturaleza de unos hechos conocidos con anterioridad al proceso (por haberlos presenciado - testigo presencial-o por haber tenido noticia de ellos por otros medios - testigos de referencia-). La Ley de Enjuiciamiento Criminal no admite este último tipo de testigos en las causas por calumnias o injurias (art. 813). 
La jurisprudencia, tanto la del Tribunal Constitucional ( $\mathrm{s}^{\mathrm{a}} 303 / 1993$, de 25 de octubre) como la de la Sala II del Tribunal Supremo (v. $\mathrm{s}^{a}$ 1176/1994, de 6 de junio), han admitido expresamente la validez y eficacia jurídicas de los testigos de referencia en el proceso penal.

La Ley de Enjuiciamiento Criminal establece la obligación de declarar (art. 410), las personas exceptuadas de dicha obligación (art. 411), las que tienen obligación de declarar, pero están exceptuadas de comparecer ante el Juez (art. 412). La imposibilidad de comparecer el testigo y la forma de obtener su testimonio en tal supuesto (art. 718.1), así como las personas que están dispensadas de declarar (art. 416 y siguientes).

Se regula también la intervención de los intérpretes (art. 440): y la forma de recibir declaración a las personas que salgan o retornen al extranjero (arts. 424 y 448), así como la de aquellas personas respecto de las que razonablemente se prevea riesgo de fallecimiento o incapacidad (art. 448).

No se harán al testigo preguntas capciosas, sugestivas o impertinentes (arts. 439 y 719). Se le dejará de narrar los hechos sin interrupción (art. 436), y deberá expresar la razón de su dicho (art. 710).

3. c) Careo. Se trata de una diligencia de carácter subsidiario, requiere inmediación judicial y es potestativa para el Juez o Tribunal, sin que tal facultad sea revisable en casación (v. ss. del T.S., Sala II, de 11 de junio y 7 de octubre de 1986, de 16 de marzo de 1987, de 4 de abril de 1984 y de 2 de marzo de 1992; asimismo la s ${ }^{\text {a }} 55 / 1984$ de 7 de mayo del Tribunal Constitucional).

4. d) Prueba pericial. Perito es la persona que, sin ser parte del proceso, emite declaraciones sobre hechos que tienen carácter procesal en el momento de su captación, para cuyo conocimiento o apreciación son necesarios o convenientes conocimientos científicos o artísticos (Sara Aragoneses: v. Derecho Procesal Penal. Andrés de la Oliva Santos y otros. CEURA. Pág. 15 y ss).

Importa destacar la posibilidad de su recusación (art. 468 y 469 L.E.Crim.). Destaca la ley que, cuando sean varios los peritos, deberán ser examinados juntos, en el supuesto de que deben declarar sobre unos mismos hechos. 
Cuando se trate de informes emitidos por organismos y entidades oficiales, de reconocida competencia y objetividad, la jurisprudencia viene entendiendo que no es precisa para su validez y eficacia jurídica la ratificación de los correspondientes informes ante la autoridad judicial, cuando obrando unidos a la causa los pertinentes informes, de modo que los mismos hayan podido ser conocidos y examinados por las partes, éstas no hayan formulado petición alguna al respecto (v. s. T.C. $n^{\circ}$ 24/1991, de 11 de febrero y ss. Sala II del T.S. de 11 de marzo y 14 de junio de 1991, 13 de marzo de 1992, 17 de febrero y 10 de junio de 1993).

5. e) Prueba documental. Ante todo, debe destacarse el concepto sumamente amplio que debe reconocerse al término "documento" (art. 726 L.E.Crim.). La sentencia del T.S. de 5 de febrero de 1988 entiende por "documento" toda cosa mueble apta para la incorporación de señales expresivas de un determinado significado.

En la sentencia de 17 de abril de 1989, se habla de las grabaciones magnetofónicas y de los vídeos y se dice que carecen de perseidad probatoria, habida cuenta de las técnicas de imitación y montaje, de modo que pueden considerarse como objeto de prueba y como "documento" en cuanto hayan sido adverados por otros medios probatorios.

6. f) La inspección ocular. Suele ser, de ordinario, una diligencia sumarial (art. 326 y ss. L.E.Crim.).

Como ha puesto de relieve la jurisprudencia, esta diligencia de prueba "en general, resulta inútil una vez concluso el sumario y transcurridos varios meses, pues no cabe ya recoger huellas o vestigios que puedan poner de relieve la forma de comisión, por vía de hipótesis, de los hechos objeto de acusación" (v. ss. de 2 de enero de 1984 y de 25 de junio de 1990).

7. g) Prueba de indicios. Se entiende por prueba indiciaria aquella que se dirige a convencer al órgano judicial de la verdad o certeza de unos hechos que no son los integrantes de la figura delictiva enjuiciada, pero de los que puede deducirse, conforme a las reglas de la lógica y de la experiencia, la realidad del delito o la participación del acusado en su comisión (v. arts. 1249 y 1253 del c. Civil y s ${ }^{a}$ T.C. no 107/1989, de 8 de junio). 
Se señalan como requisitos de este medio probatorio: a) que no se trate de indicios aislados sino que exista una pluralidad de ellos (la sentencia de 7 de julio de 1989, sin embargo, ha admitido la posibilidad de que sea válido este medio probatorio con un solo indicio cuando por su especial significación así proceda); b) que los hechos básicos han de estar plenamente acreditados mediante una prueba directa (art. 1249 del C. Civil); c) que entre el hecho demostrado (indicio) y aquél que se trate de deducir haya un enlace preciso y directo según las reglas del criterio humano (art. 1253 del C. Civil); y d) que el órgano judicial explicite en la sentencia el razonamiento en virtud del cual partiendo de los indicios o extremos directamente acreditados en la causa ha llegado a la conclusión de la certeza del hecho o del extremo de que se trate.

El Tribunal Constitucional ha admitido, expresa y reiteradamente, este medio probatorio en el campo penal (v. ss. T.C. 229/1988, de 1 de diciembre y 174 175/1985, de 17 de diciembre, entre otras).

Por último, debe destacarse que es revisable en casación la razonabilidad de la inferencia hecha por el Tribunal de instancia, la cual, por lo demás, únicamente puede ser rechazada cuando se estime ilógica, irracional o absurda, y, por ende, arbitraria (art. 9.3 C.E.).

\section{PROCEDIMIENTO PROBATORIO}

1. Dos cuestiones fundamentales han de analizarse aquí: la proposición y la práctica de la prueba. En principio, únicamente se han de practicar en el juicio oral aquellas pruebas que, habiendo sido pedidas oportunamente por las partes, hayan sido declaradas pertinentes por el órgano judicial competente (v. arts. 650, 651, 652, 659, 790.5, 791.2, 792.1 L.E.Crim.), conforme a lo especialmente previsto en la propia ley respecto de cada medio de prueba en particular.

Mas, junto a las pruebas propuestas por las partes, según dispone el art. 729.2 L.E.Crim., también se practicarán "las diligencias de prueba no propuestas por ninguna de las partes, que el Tribunal considere nece- 
sarias para la comprobación de cualquiera de los hechos que hayan sido objeto de los escritos de calificación" (art. 729. 2" L.E.Crim.). Surge así una interesante cuestión directamente emparentada con el principio acusatorio y con el derecho del justiciable a un Tribunal imparcial.

En el campo doctrinal, la mayor parte de los autores no cuestionan la posible iniciativa probatoria de los órganos jurisdiccionales, se limitan a dejar constancia de lo previsto en el art. $729.2^{\circ}$ L.E.Crim. Algunos, sin embargo, se adentran en la compleja problemática del precepto.

Gómez Orbaneja y Herce Quemada dicen que "además de las diligencias de prueba propuestas por las partes, se practicarán las que el tribunal considere necesarias para la comprobación de cualquiera de los hechos que han sido objeto del escrito de calificación (art. 729, núm. 2). El Tribunal examinará por sí mismo - y sin necesidad de que nadie se lo pida- los libros, documentos y papeles y demás piezas de convicción (art. 726). Las pruebas de cada parte se practicarán según el orden con que hayan sido propuestas: pero el presidente, aun de oficio, cuando así lo considere conveniente para el descubrimiento de la verdad, podrá alterar este orden (art. 701, ult" pf"). (v. Derecho Procesal Penal. Emilio Gómez Orbaneja y Vicente Herce Quemada. 10a Ed. Pág. 254).

Fenech, por su parte, dice que "el Juez Instructor tiene el deber de aportar al proceso cuantos medios de prueba crea conveniente para facilitar el conocimiento de los hechos objeto del proceso..."; y añade que "decretada la apertura del proceso decisorio, el Tribunal, para salvaguardar su propia imparcialidad, deja que sean normalmente las partes las que aporten nuevos medios de prueba o propongan la práctica de pruebas para el acto del juicio, de modo que la Ley no obliga al Tribunal a que tome la iniciativa de la realización de actos de prueba concretos; el Presidente, en el acto del juicio, debe acordar el careo de los testigos entre sí o con los procesados o entre éstos, y el Tribunal debe ordenar la práctica de las diligencias de prueba no propuestas por las partes que estime necesarias para la comprobación de cualquiera de los hechos que han sido objeto de los escritos de calificación (art. 729). Pero estos deberes del Tribunal o de su Presidente no son absolutos, sino que surgen o no según las 
circunstancias de cada caso y deberán ser apreciadas éstas en conciencia por el propio Tribunal”. (El proceso penal. Fenech. 1982. Pág. 93).

Ibáñez y García de Velasco, tras afirmar que en el proceso ordinario, la propuesta de pruebas queda confinada preclusivamente, al momento de las calificaciones provisionales, dice que "el Tribunal, de oficio, puede ordenar careos o cualquier otra prueba que crea necesaria para comprobar los hechos recogidos en los escritos de calificaciones provisionales que no hayan sido propuestas por las partes". (Curso de Derecho Procesal Penal. Miguel Ibáñez y García Velasco. 1969. Pág. 384).

Gimeno Sendra, al examinar la prueba, dice que "la actividad probatoria incumbe a los sujetos procesales y, de entre ellos, fundamentalmente las partes. Como consecuencia de la vigencia del principio de aportación, consustancial al sistema acusatorio, a las partes corresponde, no sólo la introducción de los hechos a través de los 'escritos de calificación”, sino también la proposición (arts. 656, 657 y 728) y ejecución de la prueba, formulando las correspondientes preguntas a testigos y peritos (arts. $708.1^{\circ}$ y 724) (iudex iudicare debet secundum allegata el probata partium). Pero en este proceso penal, el Tribunal está obligado a descubrir la verdad histórica o material y distinta, por tanto, a las que las partes pudieran representarle (verdad formal). Por esta razón, la L.E.Crim. establece una serie de correcciones al principio de aportación en beneficio de su modelo dialéctico, el de investigación... De este modo, y a diferencia de lo que acontece en el proceso civil, las partes no son dueñas de la apertura del procedimiento a prueba, debiéndose en cualquier caso, y si no hubiera conformidad, disponer el inicio de las sesiones del juicio oral (art. 701), el tribunal puede de oficio proponer la práctica de los medios de prueba (art. $729.2^{\circ}$ ), formular su Presidente preguntas a los intervinientes en la misma (art. 708.2"). disponer de oficio la diligencia de careo $\left(729.1^{\circ}\right)$ o examinar el Tribunal del mismo modo la prueba documental (art. 726)". (Derecho Procesal. Tomo II (Vol. I). El Proceso Penal. Autores: V. Gimeno Sendra. V. Moreno Catena. J. Almagro Nosete. V. Cortés Domínguez. Ed. Tirant lo Blanch. Pág. 447). 
Tomé Paule, refiriéndose a la prueba, dice que "en esta materia y en el procedimiento ordinario por delitos graves, la L.E.Crim. es rigurosa, ya que no podrán practicarse otras diligencias de prueba que las propuestas por las partes, no examinados otros testigos que los comprendidos en las listas presentadas, aunque se exceptúan de tal regla:... b) Las diligencias de prueba no propuestas cuando el Tribunal las considere necesarias para la comprobación de cualquier hecho objeto de los escritos de calificación...". (Instituciones de Derecho Procesal. Tomo tercero. Proceso Penal, 1. J. Almagro Nesete y J. Tomé Paule. Ed. Trivum. Pág. 307).

Ramos Méndez, al examinar el procedimiento probatorio y de modo particular la proposición de la prueba, afirma que "la prueba se propone por regla general en el escrito de calificación (arts. 656, 657, 790.5 L.E.Crim.) en los juicios en que existe este trámite. Pero de acuerdo con la garantía constitucional del derecho a la utilización de los medios de prueba, podría decirse que el sistema de proposición, hoy en día, hay que considerarlo abierto hasta el mismo acto del juicio oral, en la forma que ya lo permite el procedimiento abreviado (art. 793.2 L.E.Crim.). Siempre que exista posibilidad de práctica contradictoria no debe precluir la ocasión de proponer y en este sentido hay que renovar la lectura constitucional del art. 728 de la L.E.Crim. De acuerdo con los principios que rigen el proceso penal, también el Tribunal puede tomar la iniciativa probatoria. La regla general puede ser el art. 729.2 L.E.Crim. en el sentido de que es posible practicar las diligencias de prueba no propuestas por ninguna de las partes, que el Tribunal considere necesarias para la comprobación de cualquiera de los hechos que hayan sido objeto de los escritos de calificación, por lo tanto, no sólo los careos". (El Proceso Penal. Lectura Constitucional. Ed. José Mª Bosch. 1991. F. Ramos Méndez. Pág. 361).

Andrés de la Oliva, por su parte, al examinar estas cuestiones, dice que, "en la decisiva fase de "juicio oral" o 'plenario", han de practicarse, en presencia del tribunal competente, las pruebas pertinentes propuestas por las partes (acusación y défensa), pero también "las diligencias de prueba no propuestas por ninguna de las partes, que el Tribunal considere necesarias para la comprobación de cualquiera de los hechos que 
hayan sido objeto de los escritos de calificación" (art. 729.2 L.E.Crim.). Esta iniciativa probatoria del tribunal, sumamente amplia (aunque el precepto citado no se aplique con frecuencia), responde también al principio de oficialidad: la prueba no se hace depender fundamentalmente de que las partes alcen o no una carga, sino que un interés público prevalente legitima ese "deber" de llevar a cabo, incluso de oficio, la actividad probatoria necesaria para reconstruir los hechos". "No se quiere decir con esto que en el proceso penal no desempeñe ningún papel la carga de la prueba. Cabe hablar de carga de la prueba..., pero hay un deber de probar - todos los hechos relevantes- que, en la fase de "juicio oral" o de 'plenario' incumbe al tribunal". "Consecuencia o derivación primaria del principio dispositivo es la necesidad jurídica de la congruencia de la sentencia con las pretensiones de las partes... Lógicamente, cuando es, en cambio, el principio de oficialidad el que inspira la legislación y la realidad procesal, la actividad jurisdiccional no tiene por qué subordinarse de un modo igual o semejante a las pretensiones de las partes. Por eso, ha de dejarse aquí sentado, sin perjuicio de posteriores explicaciones..., que la sentencia del proceso penal debe guardar, sí, cierta correlación de las pretensiones punitivas..., pero no a causa de una inexistente disponibilidad de las partes sobre los derechos y hechos llevados al proceso, sino por exigencias procesales o de forma esencial del proceso, armónicas con el interés público que predomina, como regla, en los procesos penales, inspirados en el principio de oficialidad". "... Ha de haber correlación entre acusación y sentencia... Hay tesis distintas acerca del grado de la correlación $o$, por mejor decirlo, de la vinculación del tribunal a la acusación. Para algunos, la vinculación ha de ser absoluta. Para otros (entre los que nos encontramos), la vinculación es limitada, por entender que es preciso - y es posible- combinar la imparcialidad o neutralidad del tribunal respecto de las partes con la satisfacción del interés público consistente en una acertada persecución jurídica de los delitos. Este interés hace que el tribunal sea en cierto modo 'beligerante' respecto del objeto del proceso penal, aunque sin duda haya de propiciar la plena contradicción procesal y los derechos procesales de las partes". "Frente al principio de legalidad 
o necesidad y frente a cuanto acaba de exponerse sobre el principio de oficialidad se defiende por algunos, en nuestros días, que el proceso penal esté regido, en gran medida por el llamado 'principio de oportunidad" "A nuestro juicio, el Derecho español excluye en la actualidad que en los procesos penales se siga el principio de oportunidad. Sólo un fortísimo voluntarismo puede negar que cuando la Constitución dispone en su art. 124.2 que el Ministerio Fiscal ejerza sus funciones con sujeción al principio de legalidad está imperando, sin lugar a dudas, que el Ministerio Fiscal impulse el proceso penal y acuse siempre que se encuentre ante un hecho con apariencia delictiva y que ajuste estrictamente su acusación... a los parámetros legales". (Derecho Procesal Penal. A. de la Oliva Santos, Sara Aragoneses, Rafacl Hinojosa Segovia, Julio Muerza Esparza, José Antonio Tomé García, Colección CEURA, pág. 15 y ss.).

Recientemente, Montero Aroca ha publicado en la Revista la Ley un trabajo sobre "La garantía procesal penal y el principio acusatorio", en el que, entre otras importantes cuestiones, se refiere a "la imparcialidad del Juzgador y el principio acusatorio", afirmando que "hoy está fuera de discusión que el principio acusatorio tiene que suponer que no pueden ejercerse por un mismo órgano las funciones de investigación, en el procedimiento preliminar, y de enjuiciamiento, en el juicio, por cuanto ello supondría el riesgo de que la decisión se pronunciara por un juzgador carente de imparcialidad. En este sentido el Tribunal Europeo de Derechos Humanos, en la sentencia de 26 de octubre de 1984, en el caso De Cubber, entendió que la actuación como juez en el tribunal sentenciador de quien había sido Jucz instructor de la causa suponía la infracción del derecho a un juez imparcial, y el Tribunal Constitucional Español, en la sentencia 145/1988 de 12 de julio, declaró que "la actividad instructora, en cuanto pone al que la lleva a cabo en contacto directo con el acusado y con los hechos y datos que deben servir para averiguar el delito y sus posibles responsables, puede provocar en el ánimo del instructor, incluso a pesar de sus mejores deseos, prejuicios e impresiones a favor o en contra del acusado que influyen a la hora de sentenciar. Incluso aunque ello no suceda, es difícil evitar la impresión 
de que el Juez no acomete la función de juzgar sin la plena imparcialidad que le es exigible". En ese mismo orden de cosas, y con referencia ya al juicio, la exigencia de imparcialidad ha de llevar a que no sea el juzgador el que asume el ejercicio y concreción de la acusación: o, dicho de otro modo, la existencia de la acusación y el contenido de la misma no pueden provenir ni ser fijadas por el mismo órgano que después será el juzgador. Y la razón de ello sigue siendo la misma: garantizar la imparcialidad de quien tiene que dictar la sentencia".

Así planteadas las cosas, el principio acusatorio se resuelve en tres consecuencias trascendentes: I. No puede haber proceso si no hay acusación y ésta es formulada por persona ajena al Tribunal sentenciador. II. No puede condenarse ni por hechos distintos de los acusados ni a persona distinta de la acusada. III. No pueden atribuirse al juzgador poderes de dirección material del proceso que cuestionen su imparcialidad.

En referencia a esta última cuestión, dice Montero Aroca "la dirección material del proceso se refiere a dos aspectos distintos pero complementarios:

a) El primero de ellos atiende a la aportación de hechos al proceso. Si por el principio acusatorio corresponde a persona ajena al juzgador el determinar el objeto del proceso en su elemento de los hechos acusados, hay que llegar a la conclusión de que la aportación de los hechos no puede corresponder al Juez.

b) El segundo de ellos se refiere a la prueba de los hechos aportados por el acusador, y el reconocimiento al juzgador de facultades para contribuir con las partes a la comprobación de la verdad de esos hechos no atenta, en principio a su imparcialidad.

Antes de seguir convendría decir cuál es la solución en algunos países europeos:

1". En Alemania el parágrafo 244 ap. 2 de la STPO dice que "el Tribunal extenderá de oficio, con el fin de indagar la verdad, la práctica de la prueba a todos los hechos y medios de prueba que fueran de importancia para la resolución".

$2^{\circ}$. En Portugal el art. 340.1 del nuevo Código de proceso penal de 1987 dispone que "el tribunal ordena, de oficio o a petición de parte, la 
práctica de todos los medios de prueba cuyo conocimiento estime necesario para descubrir la verdad y bien decidir la causa".

30. En el Código procedura penal italiano de 1988, el Ministerio Público y las partes proponen los medios de prueba (art. 493) pero terminada la práctica de los mismos el juzgador puede, si lo considera absolutamente necesario, ordenar de oficio la práctica de nuevos medios (art. 507).

$4^{\circ}$. En el Derecho español, incluso en el más reciente proceso abreviado regulado en 1988, el juzgador puede disponer de oficio la práctica de cualquier medio de prueba (art. 729 y 780.1 de la L.E.Crim.).

Resulta así que en los derechos europeos se ha comprendido que las facultades atribuidas al juzgador en orden a la prueba no afectan su imparcialidad, y otra cosa muy distinta es que, siempre respecto de los hechos acotados por los acusadores: pueda colaborar para determinar la existencia o inexistencia de los mismos. El único extremo dudoso sería el relativo a cómo puede haber llegado al conocimiento del juzgador la noticia de la fuente de prueba, pero éste es tema distinto.

Si en cualquier proceso el juez pudiera utilizar sus conocimientos privados de las fuentes de prueba, para introducirlas en el proceso a través de los medios de prueba, estaríamos ante la utilización de la ciencia privada, y, con ella, ante la pérdida de imparcialidad. Ahora bien, si al juez se le atribuye la facultad de utilizar las fuentes de prueba que se derivan de la actividad realizada en el proceso, no cabe ya hablar de riesgo para la imparcialidad.

Una cosa es convertir al juez en un inquisidor o, si se prefiere, en un investigador de hechos, y otra muy distinta reconocerle la posibilidad de participar en la prueba de los hechos aducidos por las partes, utilizando para ello las fuentes de prueba que se derivan de la propia actividad procesal.

Adviértase, por último, que el procesalista se encuentra ante una situación muy próxima a la de tener doble personalidad. Por un lado se viene sosteniendo que deben aumentarse los poderes del juez civil, terminado con el juez espectador, hasta reconocerle la posibilidad de que ordene pruebas de oficio, y, al mismo tiempo y por otro lado, se dice que hay que limitar los poderes del juez penal, hasta el extremo de que no pueden ordenar pruebas de oficio, con lo que se le convierte en un 
juez pasivo. Estamos incurriendo en el absurdo de afirmar y negar una misma cosa, con lo que podemos estar muy próximos a la esquizofrenia". (La Ley 1994. I. Pág. 973).

Sobre la facultad del Tribunal penal de proponer determinadas pruebas se ha pronunciado el Tribunal Supremo en algunas recientes sentencias. Así, en la sentencia de 30 de noviembre de 1993 (Ponente Díaz Palos), dice que "... respecto a la prueba testifical, la impugna el recurrente porque los dos testigos presentes en el registro fueron traídos al juicio oral no por las partes, sino por el tribunal a quo, quien habida cuenta de la incomparecencia de tales testigos y del otrosí propuesto por el Fiscal, declaró la suspensión del juicio oral. Respecto a los testigos presenciales del registro, pero no propuestos, el a quo hizo uso de lo dispuesto en el art. $729.2^{\circ}$ de la L.E.Crim., con lo que, en sentir del recurrente, el Tribunal se convirtió en Juez y parte, puesto que, en realidad, realizó un acto de investigación propio de un acto de acusación dadas las respuestas de dichos testigos favorables a la tesis acusatoria de modo que ésta. al ser asumida por el Tribunal contradijo las condiciones de ser independiente e imparcial (s. de 18 de mayo de 1992 y las que en ella se citan). Ahora bien, la interpretación del recurrente al art. 729.2" L.E.Crim. vacía al mismo de contenido tachándolo de inconstitucional, siendo así que el T.E.D.H., en sentencia de 6 de diciembre de 1988 (caso de Barberá, Messegué y Jabardo) entendió que los artículos 315 y 729 de la L.E.Crim. habilitan tanto al Juez de Instrucción como a la Audiencia para procurarse de oficio las pruebas que estimen útiles para esclarecer la verdad, como así ocurrió con los testigos propuestos que a priori no se sabía si podían confirmar la acusación o la defensa del acusado..."

La sentencia de 1 de diciembre de 1993 (Ponente Montero Fernández-Cid) afirma que "el derecho fundamental al proceso debido legalmente, descompuesto en las plurales garantías concretas que establece el art. 24 C.E., siempre ofrece perfiles necesitados de adecuada hermenéutica. El punto de partida para examinar el elemental principio de imparcialidad objetiva del órgano jurisdiccional en el proceso penal no estará seguramente distante de estas dos perspectivas: a) La precisión de distinguir entre 
carga de la prueba e impulso probatorio; lo que es claramente palpable en la dogmática procesal alemana, singularmente respecto al proceso civil. La carga supone una precisión de actuar si se quiere evitar la producción de un perjuicio para el propio interés; en tanto que el impulso es, simplemente, algo a priori desconectado de las pretensiones en forma abstracta. Se produce prueba de varias maneras: para justificar la pretensión procesal (prueba de cargo), para desvirtuar su eficacia (prueba de descargo) o, simplemente, para contrastar, verificar otras pruebas aportadas por las partes. En este caso, se halla la posibilidad conferida al órgano jurisdiccional por el referido art. $729.2^{\circ}$ L.E.Crim. En este supuesto, la aportación probatoria (el impulso) tiene sólo como designio la 'comprobación' de los hechos. Es decir, no se dirige a probar su existencia, sino a comprobar (contraste, verificación) si la prueba sobre ellos es o no fiable desde el ángulo del art. 741 L.E.Crim., en que tal precepto se inserta. b) Así, la prueba acordada se presenta como neutral y no supone vulneración alguna del principio acusatorio, que impone la carga de la prueba a la acusación. Se trata de lo que podría denominarse 'prueba sobre la prueba' y por ello mismo su finalidad resulta descomprometida no afectante a la imparcialidad objetiva".

En la sentencia de 1 de diciembre de 1993 (Ponente Moyna Ménguez) se dice que "... la prueba testifical promovida de oficio por la Sala sentenciadora era necesaria o de posible influjo en el resultado por cuanto aportaba un nuevo y valioso indicio de cargo, y se refería a la comprobación de hechos consignados en el escrito de calificación del Ministerio Fiscal, como revelan las declaraciones sumariales del testigo..." y luego se precisa que "en definitiva, y desde el punto de vista procesal. no cabe reproche alguno contra la actuación de la Sala sentenciadora, ni podría negarse la posibilidad de recurrir en casación frente al uso de dicha facultad en el actual momento jurisprudencial, por tratarse de una facultad reglada $\mathbf{y}$ no de puro arbitrio del Tribunal de instancia, contra el criterio de las antiguas ss. de 15 de enero de 1891, 8 de enero de 1986 y 10 de junio de 1905. Sin embargo, una lectura constitucional del precepto conduciría a considerar dicha prueba como obtenida con violación de derechos fundamentales con la sanción de privación de efectos que impone el art. 11 
L.O.P.J. Ya hubo sobre esta facultad del art. $729.2^{\circ}$ encontradas opiniones de los comentaristas clásicos de la Ley de Enjuiciamiento Criminal, que deben inclinarse actualmente a favor de su inanidad por exigencia del acusatorio y del mayor rigor garantista que inspira al vigente texto constitucional. Se advierte en dicha facultad, sin gran esfuerzo argumentativo, contradicción con el principio acusatorio que gobierna el proceso penal, porque su ejercicio convierte al Tribunal en acusador o defensor según que la prueba acordada sea de cargo o de descargo...".

Más recientemente, la sentencia de 21 de marzo de 1994 (Ponente Bacigalupo Zapater) dice que “... si bien es cierto que el art. 729.2" L.E.Crim. autoriza al Tribunal a practicar las pruebas no propuestas por las partes que considere necesarias para la comprobación de cualquicra de los hechos que hayan sido objeto de acusación, no lo es menos que esta disposición encuentra su límite en el derecho del procesado a ser juzgado por un Tribunal imparcial (art. 6 C.E.D.H. y 24 C.E.). Esta garantía resulta, como es claro, desconocida cuando el Tribunal asume el papel de acusador y persecutor del acusado. Por tal motivo, el art. 729.2" L.E.Crim. no puede ser utilizado por el Tribunal en contra del acusado, ... a mayor abundamiento, se debe señalar que la S.T.E.D.H. del caso Barberá Messegué y Jabardo no es un precedente aplicable al presente, toda vez que allí no se trataba de la prueba de la acusación, sino de la prueba de la defensa. En todo caso, el derecho a la tutela judicial efectiva del acusador particular en un proceso penal no implica que el Estado deba asumir el costo de las pruebas que aquel necesite para hacer valer su pretensión. Ello es consecuencia de que el Estado provee de una adecuada defensa al interés público mediante la organización del Ministerio Fiscal...".

Como puede advertirse fácilmente, son muchas y complejas las cuestiones que plantea el art. $729.2^{\circ}$ de la Ley de Enjuiciamiento Criminal. Si, desde un punto de vista, es claro que el mismo no puede ser interpretado fuera de una perspectiva constitucional; desde otro, lo es igualmente que tampoco cabe desconocer la finalidad esencial del proceso penal: descubrir la verdad material (frente a la verdad formal). Salvado el respeto absoluto que el Tribunal sentenciador debe observar respecto de los "hechos impu- 
tados", así como a los "antecedentes" recogidos en la causa, no se comprende bien por qué el órgano judicial no puede acordar la práctica de una prueba pericial, por ejemplo, para acreditar la salud mental del acusado, cuando de la causa resulte ello necesario o procedente (y ninguna de las partes lo haya solicitado), ni por qué no puede acordar la suspensión del juicio oral ante la incomparecencia de algún testigo que, de acuerdo con los antecedentes obrantes en la causa, pudiera ser de gran transcendencia para el enjuiciamiento del hecho encausado (ante la falta de iniciativa de las partes). El respeto al principio acusatorio $y$ las exigencias inherentes al derecho a un Tribunal imparcial, desde el punto de vista de la justicia, no pueden llevar a situaciones en las que el Tribunal haya de condenar a persona respecto de la cual tenga sospechas sobre su falta de imputabilidad o a absolver al acusado respecto del cual resulten de la causa "evidencias" acerca de su responsabilidad criminal. No parece tampoco propio de un Tribunal imparcial que éste pueda acordar la práctica de pruebas que pueden favorecer al acusado $y$, en cambio, no pueda hacer lo propio con las que le puedan perjudicar (si, en ambos casos, el Tribunal respeta escrupulosamente el ámbito fáctico del juicio, delimitado por las partes, y no se sale del campo de la correspondiente investigación recogida en la causa).

1. En cuanto a la "proposición" de las pruebas, destaca Tomé García (Derecho Procesal Penal. A. de la Oliva Santos y otros. CELRA. Pág. 466) que la misma no es actividad exclusiva de las partes en el proceso penal, pues el Tribunal, de oficio, también podrá acordar la práctica de aquellas diligencias de prueba, no propuestas por ninguna de las partes, que considere necesarias para la comprobación de cualquiera de los hechos que hayan sido objeto de los escritos de calificación (art. 729.2 L.E.Crim.), y, además, examinará por sí mismo, sin necesidad de que las partes se lo pidan, los libros, documentos, papeles y demás piezas de convicción que puedan contribuir al esclarecimiento de los hechos o a la más segura investigación de la verdad (art. 726 L.E.Crim.).

En el procedimiento ordinario, las partes propondrán las pruebas de que intenten valerse, en sus escritos de calificación provisional (arts. 656 y 657 L.E.Crim.). En el acto de la vista, también pueden proponer careos (art. 
729.1 ${ }^{\circ}$ L.E.Crim.), así como cualquier diligencia de prueba que ofrezcan para acreditar alguna circunstancia que pueda influir en el valor probatorio de la declaración de un testigo (art. 729.3 L.E.Crim.). Además, podrán leerse, a instancia de cualquiera de las partes, las diligencias practicadas en el sumario, que, por causas independientes de la voluntad de aquellas, no pueden ser reproducidas en el juicio oral (art. 730 L.E.Crim.).

En el procedimiento abreviado, las pruebas se propondrán por las partes en sus escritos de acusación y de defensa, respectivamente (arts. $790.5 \mathrm{y}$ 791.2 L.E.Crim.), así como al comenzar el juicio oral (art. 793.2 L.E.Crim.).

En todo caso, el Tribunal deberá pronunciarse sobre las pruebas propuestas admitiendo las que considere pertinentes (art. 659, 790.5, 791.2 y 793.2 L.E.Crim.), debiendo razonar su decisión cuando las rechaza (art. 24. C.E.).

Para decidir sobre la pertinencia de las pruebas propuestas por las partes, el Tribunal examinará y ponderará la relación que las mismas guarden con el objeto del juicio y con lo que constituya su thema deci-

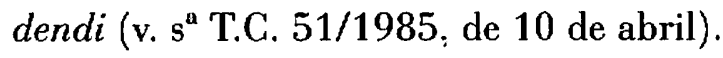

El Tribunal, al decidir sobre el particular, no puede olvidar el derecho fundamental recogido a todo justiciable a utilizar los medios de prueba pertinentes para su defensa (art. 24.2 C.E.).

No procederá recurso alguno contra el auto que admita las pruebas (art. 659, $\mathrm{pf}^{\circ} 3^{\circ}$ L.E.Crim.). Contra el auto denegatorio de alguna diligencia de prueba, podrá interponerse en su día recurso de casación, si se prepara oportunamente con la correspondiente protesta (arts. 659, $\mathrm{pf}^{\mathrm{o}} 4^{\mathrm{o}}$ y $850.1^{\circ}$ L.E.Crim.).

Dado el reconocimiento constitucional del derecho a utilizar los medios de prueba pertinentes para la defensa, también cabrá recurso frente a la decisión denegatoria del Tribunal- por infracción de precepto constitucional (v. arts. 24.2 C.E. y 5.4 L.O.P.J.), con independencia de la relevancia que también pueda tener el hecho desde la perspectiva del derecho del justiciable a la presunción de inocencia.

2. Por lo que se refiere a la práctica de las pruebas, la regla general es que deberán practicarse en el juicio oral. Ello no obstante, cabe la llamada prueba anticipada — que debe practicarse antes de la iniciación del juicio- (arts. 
657, 790.5, 791.2 L.E.Crim.), así como la prueba anticipada en la instrucción (arts. 448 y 449, en relación con los testigos; arts. 467, 471 y 476, en relación con los informes periciales; y art. 33, sobre la inspección ocular).

La Ley de Enjuiciamiento Criminal regula minuciosamente cómo se deben practicar los distintos medios de prueba.

En el procedimiento abreviado, las pruebas se practicarán concentradamente y se señala el plazo de suspensión del juicio oral admisible en los supuestos del art. 746, que será de treinta días (art. 793.4 L.E.Crim.).

3. La valoración de las pruebas compete al Tribunal sentenciador ( $v$. arts. 117.3 C.E. y 741 L.E.Crim.), pero "no surtirán efecto las pruebas obtenidas, directa o indirectamente, violentando los derechos o libertades fundamentales" (art. 11.1 L.O.P.J.).

otras clestiones relativas a la prueba EN EL proceso peNal

Examinadas sucintamente las cuestiones generales atinentes a la prueba y al procedimiento probatorio en el proceso penal, parece oportuno hacer referencia también a algunas cuestiones particulares sobre la actividad probatoria en dicho proceso y sobre la validez y eficacia probatorias de algunas diligencias procesales.

1. La primera de estas cuestiones se refiere a la distinción que debe hacerse entre las pruebas ilícitas y las pruebas simplemente irregulares. Las primeras carecen de toda validez y eficacia jurídicas y no son susceptibles de subsanación. Las segundas, por el contrario, pueden admitir la subsanación del defecto o irregularidad con que hayan sido practicadas y, en todo caso, no impiden que los hechos a que se refieren puedan ser acreditados por otros medios.

Desde el punto de vista legal, puede citarse a este respecto el art. 11.1 de la L.O.P.J., según la cual, "no surtirán efecto las pruebas obtenidas, directa o indirectamente, violentando los derechos o libertades fundamentales". En estos casos, no existe posibilidad de subsanción ni de acreditación o prueba por otros medios. 
El art. 238.3 de la citada Ley Orgánica del Poder Judicial, por su parte, establece que serán nulos de pleno derecho los actos judiciales "cuando se prescinda total y absolutamente de las normas esenciales de procedimiento establecidas por la Ley o con infracción de los principios de audiencia, asistencia y defensa, siempre que efectivamente se haya producido indefensión". En estos cásos, es posible en ocasiones la subsanación del correspondiente defecto (art. 240.2 L.O.P.J.), pero, en todo caso, ha de tenerse en cuenta que, como dispone el art. 242 de la propia Ley Orgánica: "la nulidad de un acto no implicará la de los sucesivos que fueren independientes de aquel ni la de aquellos cuyo contenido hubiese permanecido invariable aun sin haberse cometido la infracción que dio lugar a la nulidad. La nulidad de parte de un acto no implicará la de las demás del mismo que sean independientes de aquella". Se mantiene así el denominado "principio de la conservación del acto".

2. Constituye un tema frecuentemente debatido la determinación del valor probatorio de las diligencias sumariales, dado que, conforme ha declarado reiteradamente la jurisprudencia —especialmente la del Tribunal Constitucional-, en principio solamente son válidas para destruir la presunción de inocencia del acusado las pruebas practicadas en el juicio oral, ante el Tribunal sentenciador, bajo los principios de oralidad, publicidad, inmediación y contradicción (arts. 24.2 y 120 C.E. y art. 741 L.E.Crim.), siempre, en todo caso, que tales medios probatorios hayan sido traídos al proceso sin violentar derechos o libertades fundamentales del justiciable (v. ss. T.C. 31/1981, 28 de julio; 101/1985, 4 de octubre: 107/1985, de 7 de octubre; y 148/1985, 30 de octubre, entre otras).

Con independencia de esta claro principio, es de advertir que el propio Tribunal Constitucional tiene declarado que, si bien las diligencias sumariales son actos de investigación (art. 299 L.E.Crim.) y no constituyen en sí mismas pruebas de cargo, ello no comporta en modo alguno que, en orden a la actividad probatoria, haya de negarse toda eficacia a las diligencias policiales y sumariales, practicadas con las formalidades que la Constitución y el ordenamiento procesal establecen en garantía de la libre declaración y defensa de los ciudadanos, pues, de una parte, cuando dichas diligencias 
sean reproducidas en el acto de la vista en condiciones que permitan a la defensa del acusado someterlas a contradicción, pueden constituir medios de prueba válidos para desvirtuar la presunción de inocencia (v. ss. T.C. 80/1986, de 17 de junio; 82/88, de 28 de abril; y 137/1988, de 7 de julio).

De otra parte, cuando las diligencias o actuaciones sumariales son de imposible o muy difícil reproducción en el juicio oral, es lícito traerlas al mismo como prueba anticipada o preconstituida, siempre y cuando se haya posibilitado el ejercicio del principio de contradicción en los términos señalados por el art. 730 de la L.E.Crim., esto es, solicitando su lectura en el juicio oral (v. s. T.C. 62/1985, de 10 de mayo). "puesto que, estando sujeto también el proceso penal al principio de búsqueda de la verdad material, es preciso asegurar que no se pierdan datos o elementos de convicción, utilizando en estos casos la documentación oportuna del acto de investigación, llevado a cabo, en todo caso, con observancia de las garantías necesarias para la defensa" (v. s" T.C. 201/1989, de 30 de noviembre).

En cualquier caso, debe ponerse de manifiesto que cuando a lo largo del proceso se produzcan variaciones e incluso contradicciones en las declaraciones de imputados y testigos, corresponde al Tribunal sentenciador la facultad de examinarlas, ponderarlas $y$, en definitiva, formar luego libremente su convicción, pudiendo, en consecuencia, aceptar la versión que, en función de todas las circunstancias concurrentes, estimen veraz, con independencia del momento procesal en que la misma se haya producido.

3. La diligencia de entrada y registro en el domicilio de los particulares ha dado origen también a diversas interpretaciones doctrinales y jurisprudenciales, cuando la misma no ha respetado íntegramente las exigencias legales y constitucionales.

Diversas son las irregularidades u omisiones de exigencias legales de que esta diligencia puede adolecer. Hay unanimidad en admitir que, cuando falta la autorización judicial, la diligencia es ilícita e insubsanable, siendo de aplicación en tal caso el art. 11.1 L.O.P.J.

La ausencia del Secretario Judicial en la práctica de la diligencia fue valorada de forma diversa, dada la exigencia de su presencia, en todo caso, conforme al texto derogado del art. 569 L.E.C.rim. Para unos, 
dicha ausencia hacía ilícita la diligencia, con las consecuencias ya analizadas. Para otros, la diligencia era nula, el acta correspondiente carecía de todo valor probatorio, pero ello no impedía que los hechos descubiertos en la misma pudieran ser acreditados ante el Tribunal por otros medios probatorios, tales como el reconocimiento por el propio inculpado o por medio del testimonio de los testigos presenciales de aquella irregular diligencia. La jurisprudencia, no obstante, declaró que a estos efectos no era válido el testimonio de los funcionarios de Policía que. como delegados del Juez, llevaron a cabo la diligencia.

Tras la reforma operada en el citado art. 569 L.E.Crim., la jurisprudencia ha sentado la siguiente doctrina, recogida en la sentencia de la Sala II del T.S. de 22 de abril de 1994. Esta sentencia mantiene, como no podía ser menos, la anterior doctrina para los casos en que el registro domiciliario se lleve a efecto sin la previa autorización judicial (art. 18.2 C.E.; art. 545 y ss. L.E.Crim.; y art. 11.1 L.O.P.J.). No obstante, cuando no concurra a la diligencia el Secretario Judicial, como quiera que, de acuerdo con el nuevo texto, tal presencia no es obligada en todo caso, ya que el Juez puede autorizar que un funcionario de la Policía Judicial $u$ otro funcionario público haga sus veces y extienda el acta correspondiente, en estos casos el acta carecerá de fehaciencia (que únicamente puede darla la intervención del Secretario Judicial —art. 281.1 LOPJ-), pero nada impide que los funcionarios de policía puedan ratificar - como testigos válidos- ante el Tribunal, el contenido de la misma.

4. En materia de interceptación de las comunicaciones telefónicas, la regulación legal de nuestro ordenamiento jurídico es sumamente deficiente, prácticamente se limita a la prevención constitucional, según la cual "se garantiza el secreto de las comunicaciones y, en especial, de las postales, telegráficas y telefónicas, salvo resolución judicial" (art. 18.3 C.E.), y a lo dispuesto en el art. 579.3 L.E.Crim. ("De igual forma, el Juez podrá acordar, en resolución motivada, por un plazo de hasta tres meses prorrogables por iguales periodos, la observación de las comunicaciones postales, telegráficas o telefónicas de las personas sobre las que existan indicios de responsabildad criminal, así como de las comunica- 
ciones de las que se sirvan para la realización de sus fines delictivos").

Se echa en falta, en nuestro Derecho, la existencia de unas reglas claras y detalladas en esta materia (personas susceptibles de ser sometidas a escucha judicial, naturaleza de las infracciones que puedan dar lugar a la misma, precauciones a tomar para conservar intactos y completos los registros realizados a los fines del control eventual por el Juez, requisitos para poder acordar la destrucción de las bandas de grabación, etc.), como considera necesario el TEDH (v. ss. de 24 de abril de 1990, casos Huvig y Kruslin).

El auto de la Sala II del T.S., de fecha 18 de junio de 1992, dictado en el llamado "caso Naseiro", analiza esta materia con gran detalle y entiende exigibles - para la validez y eficacia probatoria de esta diligencia- la previa autorización judicial, debidamente motivada, que la misma sea proporcional a la gravedad del hecho a investigar, que exista un directo control judicial, que sean entregadas al Juez la integridad de las cintas de grabación originales, que el Secretario Judicial certifique la transcripción escrita de las mismas y que se lleve a cabo una audición de las mismas con intervención de los interesados y con plenas garantías de defensa.

Pese a la relevancia que debe reconocerse a esta importante resolución del Tribunal Supremo, es indudable que - como se ha dicho- la materia demanda una más detallada regulación legal, y que la doctrina sentada en aquella necesita determinadas precisiones en algunos aspectos, como el referente a la selección de los pasajes con relevancia a los efectos del enjuiciamiento de los hechos investigados. Ya el Tribunal Europeo de Derechos Humanos habla de control eventual por el Juez (v. $s^{\mathrm{a}}$ recaída en el caso Huvig; antes citada), y parece evidente que, en múltiples ocasiones, será imposible que el Juez de Instrucción pueda dedicar el tiempo necesario para efectuar una audición completa de todas las grabaciones que haya autorizado y una selección de los pasajes judicialmente relevantes a los fines de la investigación perseguida, cuyas peculiaridades son conocidas mejor por la policía que por el Juez en las fases iniciales de la investigación. 
Morenilla Rodríguez con referencia a la jurisprudencia del Tribunal Europeo de Derechos Humanos, dice que el derecho al secreto de la correspondencia está reconocido expresamente en el art. 8 del Convenio Europeo y que las demás formas de interferencias en las comunicaciones no escritas se han considerado contrarias al derecho al respeto de la vida privada. Y, al respecto, cita la sentencia de TEDH, caso KLASS y otros, de 1978, relativa a las escuchas telefónicas, en la que dicho Tribunal declaró que: "aunque el párrafo 1 del art. 8 no menciona las conversaciones telefónicas, estimaba con la Comisión que estaban comprendidas en las nociones de 'vida privada' y de 'correspondencia' e incluso que pueden traducirse también en una injerencia en el ejercicio del derecho de una persona al respeto de su domicilio"; añadiendo que esta doctrina se ha confirmado en posteriores sentencias relativas a las escuchas telefónicas (casos MALONE, KRUSLIN, HUVIG y LÜDI).

Dice Morenilla que, en la sentencia KLASS y otros, el Tribunal Europeo de Derechos Humanos estableció una doctrina completa sobre la justificación, procedimiento y control de las escuchas telefónicas, resaltando que: "los Estados contratantes no disponen de una discrecionalidad ilimitada para someter a medidas de vigilancia secreta a las personas dentro de su jurisdicción", y que: "cualquiera que sea el sistema de vigilancia seguido, el Tribunal debe convencerse de la existencia de garantías adecuadas contra los abusos. Esta apreciación no reviste un carácter relativo: depende de todas las circunstancias de la causa; por ejemplo la naturaleza, extensión y duración de las medidas eventuales, las razones tenidas en cuenta para ordenarlas, las autoridades competentes para permitirlas, ejecutarlas o controlarlas y el tipo de recursos disponibles según el derecho interno". En cualquier caso, se dice que en la sentencia de referencia que "al establecer una interpretación a un derecho garantizado por el Convenio exige una interpretación estricta".

En suma, sostiene el citado autor, que constituyen requisitos que pueden justificar la injerencia en el ejercicio de este derecho los siguientes: $A$ ) La injerencia ha de estar prevista por la ley. B) Dicha injerencia ha de constituir una medida que en una sociedad democrática sea necesaria 
para: 1 . la seguridad nacional; 2. para la seguridad pública; 3. para el bienestar económico del país; 4. para la protección de la salud; 5. para protección de la moral; y 6 . para la protección de los derechos y libertades de los demás (art. 8, párrafo $2^{\prime \prime}$ del convenio). destacando, ello no obstante, que la enunciación de fines no es un estricto "numerus clausus”. Se destaca, en este sentido, que las sociedades democráticas se encuentran amenazadas en nuestros días por formas muy complejas de espionaje y por el terrorismo, de manera que el Estado debe ser capaz, para combatir eficazmente esas amenazas, de vigilar en secreto los elementos subversivos que operan en su territorio. Y, C) . Vecesidad y proporcionalidad de la injerencia en una sociedad democrática. (v. J. M Morenilla Rodríguez: “El derecho al respeto de la esfera privada en la jurisprudencia del Tribunal Europeo de Derechos Humanos". La Jurisprudencia del Tribunal Europeo de Derechos Humanos. Consejo General del Poder Judicial. 1993. Págs. 317 y ss.).

En este contexto, estimo que, partiendo de la actual normativa (al margen de lo especialmente previsto para los supuestos de investigación de hechos delictivos cometidos por bandas armadas o elementos terroristas o rebeldes -art. 579.4 L.E.C.rim.-), previa la pertinente autorización judicial, que deberá revestir la forma de auto, debidamente motivado, en el que hayan sido examinadas las exigencias inherentes al principio de proporcionalidad, con precisa determinación del número telefónico y persona cuyas conversaciones se pretendan observar y registrar, así como del concreto hecho a investigar, para lo que la Policía, en su caso, facilitará al Juez el mayor número de elementos de juicio sobre el particular, se llevará a cabo la intervención autorizada $\mathrm{u}$ ordenada por los correspondientes funcionarios policiales, que darán cuenta al Juez, en la forma por éste determinada, de la marcha y resultados de la intervención, y, concluida ésta, entregarán al Juez las cintas originales, junto con las copias de la misma relativas a los pasajes que consideren de interés a los fines investigados.

Una vez las cintas en poder del Juez de Instrucción, éste convocará a una diligencia de audición de las cintas, con presencia del Ministerio Fiscal y de los interesados con sus Letrados (de libre designación o de oficio, en su caso). Los interesados manifestarán si reconocen la autenticidad de sus 
voces y el contenido de las conversaciones; y si negasen la primera, podrá acordarse la pertinente prueba pericial. En todo caso, harán las precisiones que estimen pertinentes, tanto los interesados como el Ministerio Fiscal y los Letrados. Tanto éstos como el propio Juez podrán solicitar y acordar, respectivamente, la audición de las cintas originales, tanto para comprobar la fidelidad de las copias parciales como para poder adicionar a las mismas los extremos que estimen precisos. Finalmente el Secretario Judicial certificará el contenido de las correspondientes transcripciones escritas.

Practicada esta diligencia, sería conveniente —en función de las circunstancias concurrentes en cada caso- acordar motivadamente la destrucción de las partes de las cintas originales que no havan sido oídas o que se hayan estimado innecesarias o improcedentes para el enjuiciamiento de los hechos perseguidos. Resolución recurrible, en todo caso, ante el órgano judicial que haya de enjuiciar el caso.

Debe reiterarse, en todo caso, la necesidad de que esta materia sea regulada legalmente con la precisión y claridad que demanda la gravedad del atentado que estas diligencias suponen siempre para la vida privada de las personas.

5. Respecto del testimonio de personas residentes en el extranjero, y de su posible eficacia probatoria, es preciso atender a las circunstancias concurrentes en cada caso. Pocas dudas pueden ofrecer los supuestos en que se haya efectuado en la forma prevenida en el art. 448 L.E.Crim. Mayores dificultades puede of recer el supuesto de que el testimonio haya sido prestado ante las autoridades judiciales de otro Estado. Sobre esta cuestión, así como sobre los testigos de referencia, puede consultarse la interesante sentencia de la Sala II del T.S. de 6 de junio de 1994 (que lleva el número 859/94 de las de dicha Sala).

6. En cuanto a las diligencias policiales sobre medición de alcohol en sangre, el Tribunal Constitucional exige, para su validez y eficacia probatoria, que se haya practicado con las debidas garantías, informando en todo caso al interesado de la posibilidad de una segunda medición y posible análisis de sangre ( $\mathrm{s}^{\mathrm{a}}$ T.C. 145/1987, de 27 de septiembre, entre otras), así como la necesidad de que dicha diligencia sea ratificada ulteriormente 
en el curso del procedimiento judicial ( $\mathrm{s}^{\mathrm{a}}$ T.C. 19/1988, de 16 de febrero).

7. En orden a las filmaciones videográficas, y fotográficas, cuando no se cuente con autorización judicial previa, entiende la jurisprudencia que están permitidas siempre que se lleven a efecto en espacios libres y públicos. Pueden examinarse, sobre el particular, las sentencias de 6 de mayo de 1993, 14 de enero y 6 de abril de 1994.

8. Sobre las grabaciones magnetofónicas, dice la sentencia del Tribunal Constitucional 190/1992, de 16 de noviembre, que "con carácter general, debe reconocerse que toda grabación magnetofónica presenta una posibilidad cierta de manipulación, trucaje y distorsión del contexto global en el que tuvieron lugar las manifestaciones reproducidas, siendo perfectamente concebible que en ellas se imite la voz de una persona al objeto de atribuirle unas declaraciones de las que no fue autor $y$ que, incluso, nunca se produjeron. Mas una cosa es que, para evitar la proliferación de "pruebas" artificiosamente conseguidas, se recomiende proceder con suma cautela a la hora de admitir como tales las manifestaciones contenidas en uno de estos soportes, y otra bien distinta es que deba negárseles radicalmente toda eficacia probatoria".

En suma. pues, las grabaciones magnetofónicas pueden ser: a) objeto de prueba (en cuanto pericialmente se estime que la imagen o la voz corresponden de modo efectivo a la persona). o b) "documento" (cuando su reproducción de un hecho pasado sea adverada por distintos medios probatorios,cual el testifical) (v. s ${ }^{\text {a }}$ T.S. de 30 de noviembre de 1992).

9. Por último, vamos a hacer referencia a los informes periciales emitidos por organismos oficiales, aportados a la causa en la fase de instrucción, por cuanto la jurisprudencia de la Sala II tiene declarado que cuando unidos a las actuaciones hayan sido conocidos por las partes, sin que las mismas hayan hecho observación alguna al respecto, interesado su ratificación o reproducción, o propuesto otras diligencias con finalidad impugnatoria, aquellos pueden ser valorados por el Tribunal sentenciador para formar su convicción sobre la realidad de los hechos enjuiciados, si son traídos al plenario como prueba documental, pues, conforme a la buena fe procesal (art. 11.1 L.O.P.J.), no es permisible alegar la falta de contradic- 
ción de tal prueba cuando quien lo hace tuvo oportunidad de proponerla para el acto de la vista. Pueden examinarse a este respecto, entre otras, las ss. 24/1991, de 11 de febrero del Tribunal Constitucional, y las ss. 19 de febrero y 13 de marzo de 1992 de la Sala II del T.S., entre otras muchas.

Sin duda, no son las anteriores las únicas cuestiones que deben merecer nuestra atención, al examinar la problemática de la prueba en el proceso penal, mas el carácter global de esta exposición y su limitación temporal no permiten pretender siquiera un desarrollo más amplio del tema propuesto, del que, salvo algunos extremos singulares, nos hemos limitado a dar una visión panorámica y necesariamente insuficiente. 